\title{
Hypertrophic olivary degeneration: unveiling the triangle of Guillain-Mollaret
}

Degeneração olivar hipertrófica: descobrindo o triângulo de Guillain-Mollaret

William Alves Martins' , Luiz Carlos Porcello Marrone ${ }^{1,3}$, Ricardo Bernardi Soder1,3, Jaderson Costa da Costa1,2,3

A 28-year-old woman presented with hemi-dystonic movements on the left. Four years earlier, a ruptured vascular malformation caused a hemorrhagic stroke on the left cerebellar hemisphere (Figure 1B), evacuated by surgery. MRI revealed right hypertrophic olivary degeneration (HOD) (Figure 1A) and reduction of cerebellar-rubro pathways (Figure 2).
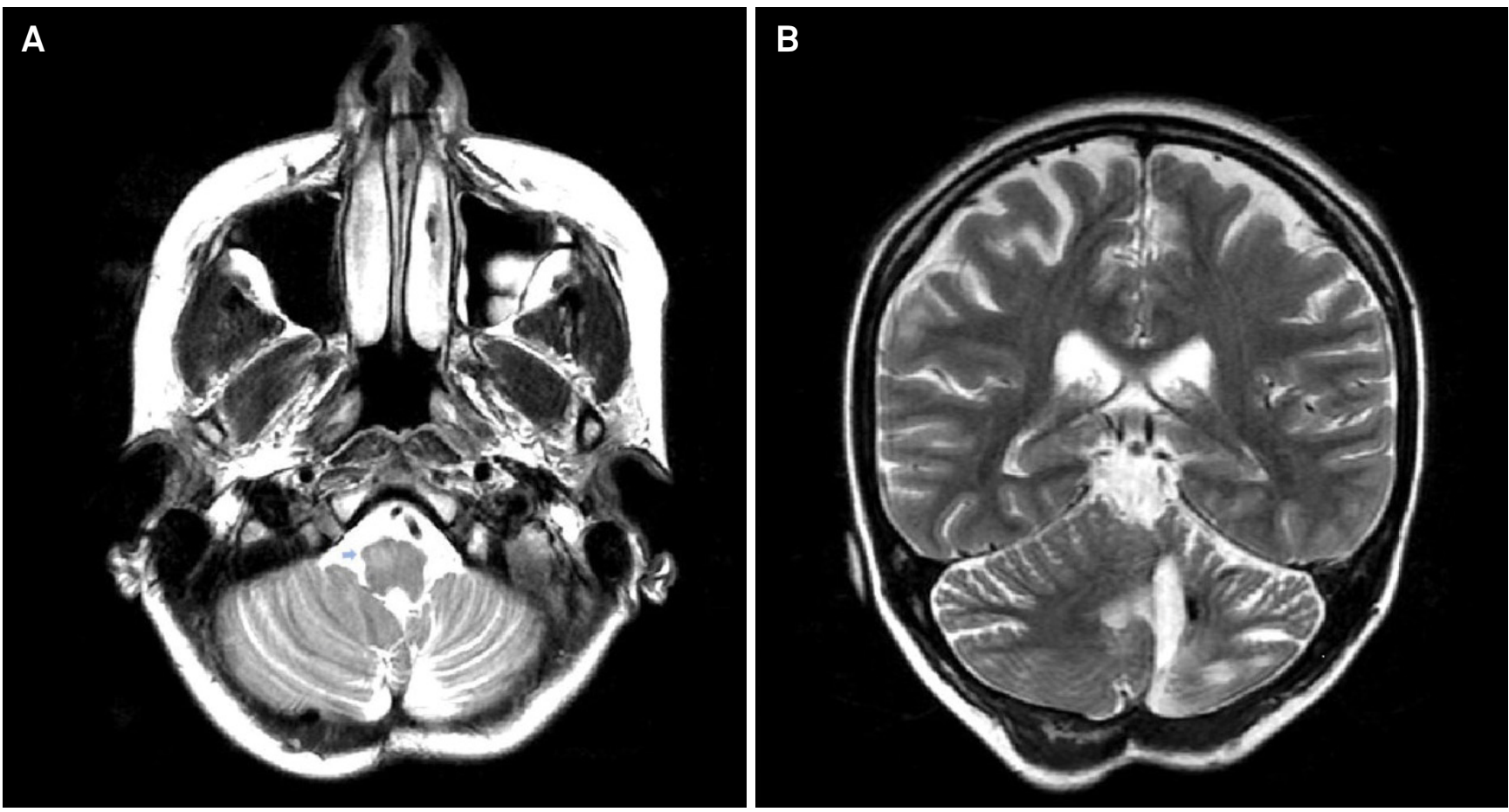

Figure 1. (A) Axial T2-weighted image showing enlargement and hyperintensity of the right olivary nuclei, compatible to hypertrophic olivary degeneration; (B) Coronal T2-weighted image displaying reduced left cerebellar hemisphere associated to hemosiderin.
HOD is a trans-synaptic degeneration affecting the dentate-rubro-olivary pathway or Guillain-Mollaret's triangle $^{1}$. A lesion in any part of this synaptic pathway may lead to HOD (Figure 3), including stroke, cranioencephalic trauma, neurodegenerative diseases, inflammatory illnesses, among others ${ }^{2,3}$. This unique synaptic collapse is associated to palatal myoclonus, parkinsonian features and dystonia ${ }^{1,2}$.

Pontifícia Universidade Católica do Rio Grande do Sul, Hospital São Lucas, Departamento de Neurologia, Porto Alegre RS, Brasil;

${ }^{2}$ Pontifícia Universidade Católica do Rio Grande do Sul, Faculdade de Medicina, Departamento de Medicina Interna, Porto Alegre RS, Brasil;

${ }^{3}$ Pontifícia Universidade Católica do Rio Grande do Sul, Instituto do Cérebro, Porto Alegre RS, Brasil.

Correspondence: William Alves Martins; Departmento de Neurologia, Hospital São Lucas - PUCRS; Avenida Ipiranga 6690/220;00610-000 Porto Alegre RS, Brasil; Email: walvesm.br@gmail.com

Conflict of interest: There is no conflicts of interest to declare.

Received 22 August 2015; Received in final form 29 November 2015; Accepted 09 December 2015. 

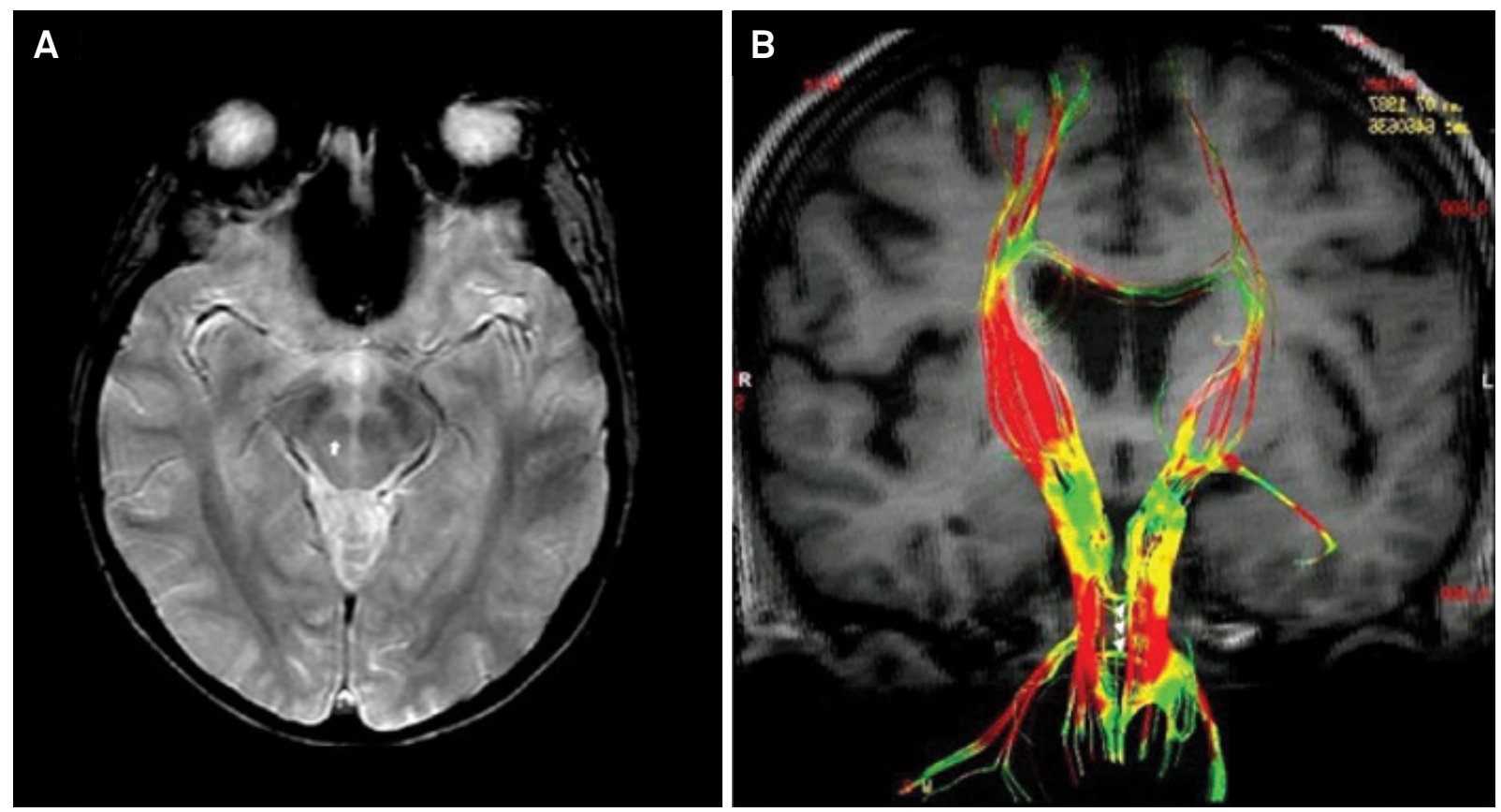

Figure 2. (A) Atrophy of right red nucleus (arrow) and substantia nigra; (B) Tractography image showing decreased volume of the right central tegmental tract (arrowheads).

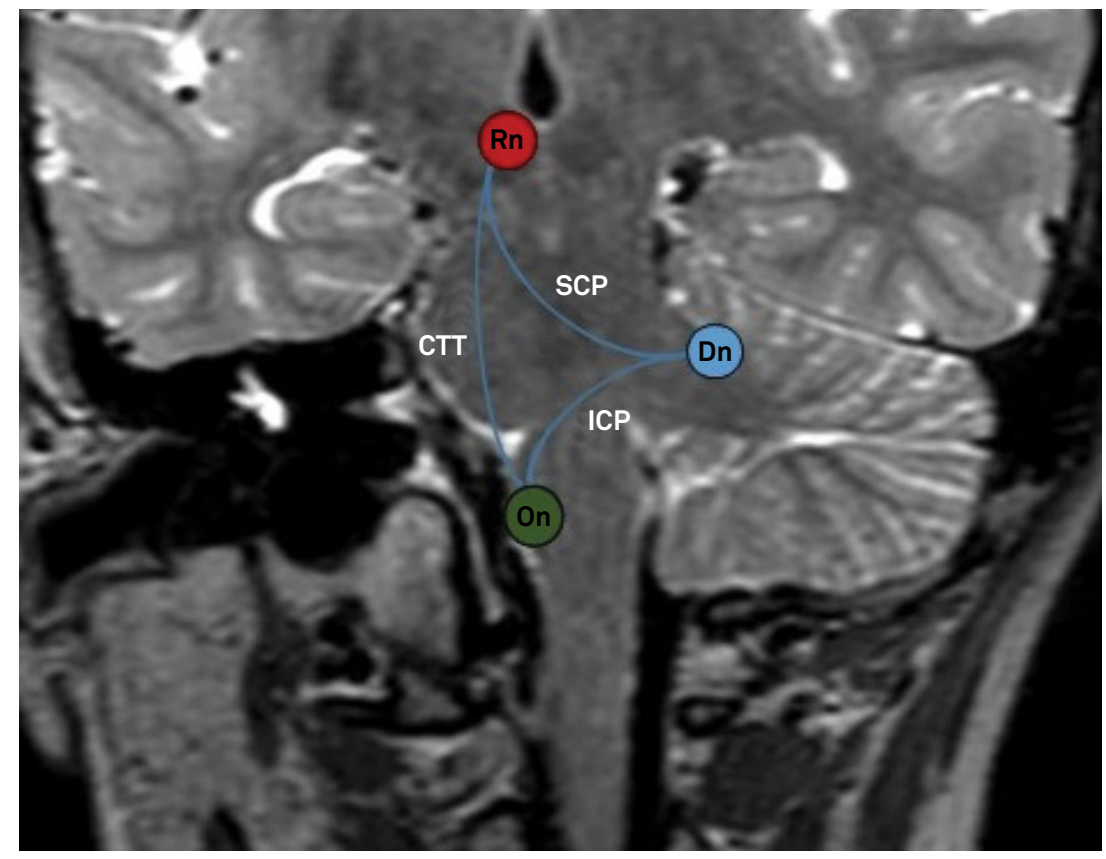

Figure 3. Anatomical view of the Triangle of Guillain-Mollaret. Initially, the axons from the dentate nucleus of cerebellum travel through the superior cerebellar peduncle (SCP) and decussate in the brachium conjunctivum to terminate into the contralateral red nucleus (Rn). Then, the central tegmental tract (CTT) leaves the red nucleus in the direction of the ipsilateral inferior olivary nuclei (On), situated downwardly at the medulla oblongata. At last, the inferior cerebellar peduncle (ICP) connects the ION to the opposite dentate nucleus (Dn), closing this complex pathway known as dentate-rubral-olivary circuitry.

\section{References}

1. Guillain G, Mollaret P. Deux-cas de myoclonies synchrones et rhythmes velopharyngo-laringo-oculo-diaphragmatiques. Rev Neurol. 1931;2:545-66.

2. Martins WA, Schilling LCP, Neto FK, Becker J. Hypertrophic olivary degeneration secondary to Neuro-Behçet's disease.
Clin Neuroradiol. 2015 Mar 24 [Epub ahead of print] doi:10.1007/s00062-015-0384-0

3. Siebert E, Harms L, Herbst M. Posttraumatic bilateral hypertrophic olivary degeneration. Neurol Sci. 2013;34(10):1829-30. doi:10.1007/s10072-013-1309-9 